\title{
Desafios do trabalho docente na Educação de Jovens e Adultos: vivências da prática de ensino em Ciências Biológicas
}

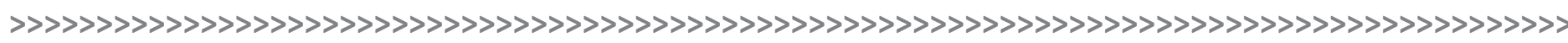

\author{
Evelin Christine Fonseca de Souza* \\ Gil Cardoso Costa** \\ Camilo José Ugarte Bornstein ${ }^{* * *}$
}

\section{Resumo:}

A Educação de Jovens e Adultos tem como uma de suas principais características a heterogeneidade de seu alunado, o que traz desafios únicos para o trabalho docente. Durante a prática de ensino em um colégio público estadual no município do Rio de Janeiro, acompanhamos as aulas de Biologia das turmas de primeiro e terceiro anos do ensino médio em ambos os semestres de 2011 nessa modalidade de ensino. Identificamos desafios categorizados em linguístico, sociocultural, de atenção, continuidade e motivacional - que a professora, os alunos e nós, licenciandos, vivenciamos. Esses desafios são analisados e ilustrados com relatos baseados em experiências vividas durante a prática de ensino.

\section{Palavras-chave:}

Educação de Jovens e Adultos. Prática de ensino. Biologia. Relato de experiência.

\begin{abstract}
:
One of the main features of Youth and Adult Education consists on its students' heterogeneity, leading to specific challenges that teachers must face. During teaching practice in a nocturnal public state school of Rio de Janeiro, we have followed high school's first and third grade Biology classes along both semesters of 2011. We have identified some challenges - classified into linguistic, sociocultural, attention, continuity, and motivational - that the teacher, the students, and us, Biology undergraduate students pursuing a teaching degree, have passed through. These challenges are analyzed and illustrated by reports based on experiences we have lived during the teaching practice.
\end{abstract}

\section{Keywords:}

Youth and Adult Education. Teaching practice. Biology. Experience report.

\section{Introdução}

No âmbito histórico, a Educação de Jovens e Adultos (EJA) no Brasil remonta ao início da colonização portuguesa, com o processo de alfabetização de indígenas, liderado pelos jesuítas, quando chegaram, em 1549. Entretanto, foi apenas a partir do século XX que o governo brasileiro desenvolveu programas educacionais específicos para essa faixa etária. O foco inicial consistia na alfabetização, porém, com o crescente desenvolvimento industrial e tecnológico, passou à qualificação de mão de obra (LOPES; SOUZA, 2005, p. 3-4), além de estimular a formação da identidade do indivíduo e sua inclusão em diferentes

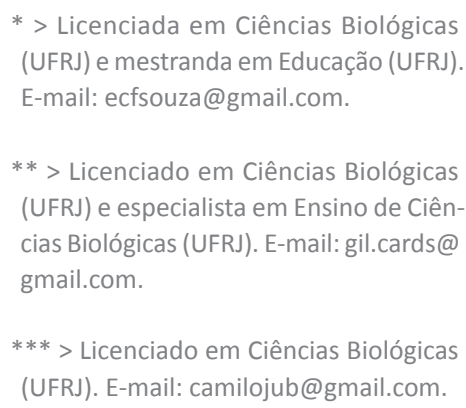

* > Licenciada em Ciências Biológicas (UFRJ) e mestranda em Educação (UFRJ). E-mail: ecfsouza@gmail.com.

** > Licenciado em Ciências Biológicas (UFRJ) e especialista em Ensino de Ciências Biológicas (UFRJ).E-mail: gil.cards@ gmail.com.

*** > Licenciado em Ciências Biológicas (UFRJ). E-mail: camilojub@gmail.com. 
setores da sociedade. Dessa forma, os programas elaborados pelo governo que atualmente caracterizam a EJA visam a garantir não apenas a alfabetização, mas cursos e exames de ensino fundamental e médio e educação à distância para aqueles que não realizaram ou concluíram os estudos na idade esperada (VIEIRA, 2011, p. 14).

De acordo com Ribeiro (1999, p. 185), os alunos da EJA possuem características e necessidades distintas, se comparadas às do público do ensino regular. A diversidade do alunado é marcante: indivíduos de diferentes culturas, crenças, origens socioeconômicas, idades e expectativas quanto à escola coexistem no ambiente escolar. O lastro de conhecimento que trazem é maior, se comparado ao de crianças e adolescentes, em consequência de suas experiências de vida. Logo, as especificidades do alunado jovem e adulto exigem estratégias de ensino diferenciadas, preferencialmente, conjugando suas vivências aos conteúdos. Exemplo disso é a ênfase que o documento de Reorientação Curricular para a EJA no ensino médio atribui à necessidade de elaboração de um programa compacto e diretamente ligado à realidade do aluno, com aulas partindo da problematização de situações reais, através do uso de linguagem acessível para o público ao qual se destina (DOTTORI, 2006, p. 100).

\section{Contextualização da prática de ensino}

Enquanto licenciandos em Ciências Biológicas pela Universidade Federal do Rio de Janeiro, realizamos a prática de ensino (no período de março a novembro de 2011) em uma escola estadual noturna da modalidade EJA, que se localiza na zona sul do município do Rio de Janeiro. Cada semestre correspondeu a um ano letivo do ensino regular, de maneira que pudemos acompanhar quatro turmas de primeiro ano e duas de terceiro ano do ensino médio em cada semestre. O número de alunos que acompanhamos variou, no primeiro semestre, de 212 matriculados no primeiro ano para 133 que chegaram ao fim do semestre letivo e, no terceiro ano, de 102 matriculados para 72. Já no segundo semestre, foram 196 alunos matriculados no primeiro ano e 113 que efetivamente concluíram o semestre letivo, enquanto no terceiro ano tivemos 91 alunos matriculados e 61 concluintes. A amplitude etária dos alunos era de 18 a 75 anos, mas a maioria possuía entre 18 e 25 anos, fato já observado por Vieira (2011, p. 93) em pesquisa realizada no mesmo colégio, no ano de 2010, em que 54\% dos 261 alunos que responderam ao questionário aplicado pela pesquisadora pertenciam à referida faixa etária. Tal dado corrobora o fenômeno de 'rejuvenescimento' da EJA, apontado por alguns autores (NASCIMENTO, 2001, p. 14; BRUNEL, 2004, p. 96; VALE, 2007, p. 51-54; SILVA, 2010, p. 8).

De modo geral, os alunos mais jovens desejavam concluir o ensino médio para obter o certificado de conclusão e pleitear uma vaga no mercado de trabalho ou, em casos mais raros, em instituições de ensino superior. Por sua vez, os adultos buscavam o certificado para garantir a permanência no emprego, por exigência dos patrões, ou aprimoramento profissional para obtenção de funções com melhor remuneração. Os alunos com mais de quarenta anos, principalmente do sexo feminino, justificavam o regresso à escola pela satisfação pessoal de concluir os estudos e encontrar na escola um espaço de aprendizado e socialização.

Através de observações durante a prática de ensino, foi possível detectar alguns desafios com os quais os alunos, a professora regente e nós, licenciandos, nos deparamos durante o processo de ensino e aprendizagem. Esses desafios foram divididos em cinco categorias - linguístico, sociocultural, de atenção, continuidade e motivacional - e trazem exemplos de casos vividos em sala de aula, bem como de reflexões e soluções que consideramos adequadas para lidar com tais desafios. 


\section{Desafio linguístico}

A dificuldade dos alunos com aspectos da linguagem foi observada no âmbito da escrita, leitura e interpretação de textos. O déficit nessas habilidades provavelmente tem origem em uma base comprometida pelas descontinuidades em seus processos de escolarização e falta de prática cotidiana em leitura e escrita. Ademais, além de estruturas textuais específicas como a ausência de narrador e a nominalização (substituição de verbos por grupos nominais), que expressam ações e processos científicos supostamente cristalizados (MORTIMER, 1998, p. 102-103), a disciplina escolar Biologia possui um conjunto de termos específicos que não são usados cotidianamente. Expressões como mitocôndria, procarionte e quimiossintese não fazem parte da linguagem cotidiana dos alunos, o que dificulta a apreensão dos termos e de seus significados.

Durante provas e trabalhos escritos, foi possível perceber a dificuldade que os alunos apresentavam na interpretação dos enunciados - era necessário que nós ou os professores lêssemos as perguntas, para que boa parte dos alunos pudesse entendê-las, por mais que a leitura fosse fiel ao texto, sem apresentar nenhum acréscimo de informações ou mediações.

Além disso, a correção de alguns trabalhos e provas evidenciou mais uma vez a falta de intimidade dos alunos com a linguagem escrita. As redações apresentavam frases desconexas, argumentos contraditórios e variados tipos de inadequações gramaticais e ortográficas, tornando-as muitas vezes incompreensíveis. O exemplo abaixo sintetiza alguns dos itens discutidos. Ele foi redigido por uma aluna do primeiro ano a partir do seguinte enunciado: "Considerando as hipóteses de origem da vida apresentadas em aula, elabore uma redação mencionando qual hipótese você considera mais provável e explique por que não acredita que as demais possam ser reais". A redação está fielmente representada neste trabalho, sem alterações na disposição das frases:

"Eu acredito que deus criou tudo

a terra o homem, ir também deu

sua propria vida por nós.

Sabemos que esta sempre ao nosso lado

Nunca deixa um filho dele sem

resposta ir tambem esta sempre pra

Potegem das coisas ruir.

Eu sei que a ciencias cuidar mais da mendicina"

Tendo em vista as dificuldades em leitura, escrita e interpretação de texto, algumas estratégias eram utilizadas para facilitar a compreensão do conteúdo. A assimilação dos termos biológicos era facilitada pela associação das unidades formadoras de palavras a funções e relações já estabelecidas anteriormente pelos alunos. Para facilitar a compreensão do termo homozigoto, por exemplo, a professora regente separava as unidades mórficas homo e zigoto e relacionava a primeira à palavra homossexual, ou seja, aquele que sente atração por alguém do mesmo sexo. Dessa forma, os alunos compreendiam que o termo homozigoto se refere a alelos sempre iguais ("AA" ou "aa", por exemplo).

Uma das estratégias mais enfatizadas pela professora regente era a elaboração de textos de fácil entendimento para os alunos. Dessa forma, uma de nossas maiores preocupações, durante a pré-regência e a regência, consistiu no cuidado em elaborar textos de apoio com o conteúdo de cada aula e questões de provas com frases curtas e objetivas, facilmente inteligíveis. Nosso objetivo era permitir que os alunos tivessem condições de ler o material sozinhos, sem que a composição do texto trouxesse qualquer tipo de impedimento para a compreensão da matéria. 


\section{Desafio sociocultural}

A heterogeneidade é uma das características mais acentuadas do alunado jovem e adulto. Isso faz com que sejam trazidas experiências únicas para a sala de aula que contribuem de maneira muito instigante para a contextualização do conteúdo. Por vezes, seus relatos e suas vivências são conflitantes com o enfoque científico dado pelo professor e, outras vezes, corroboram com esse enfoque, enriquecendo em ambos os casos o diálogo e o processo de ensino-aprendizagem.

As situações nas quais percebemos ampla participação dos alunos diziam respeito a temas e ideias do senso comum que estão, ou não, em desacordo com a ciência. Em ambos os casos, havia conflitos constantes entre a visão que traziam e a visão científica passada pelo professor.

Um dos exemplos mais emblemáticos foi observado durante a aplicação de um estudo dirigido sobre conceitos genéticos ligados a alelos recessivos e dominantes. Durante a atividade, uma aluna leu o enunciado em voz alta e montou o cruzamento pedido ignorando as informações fornecidas, elaborando-o com base no seguinte raciocínio exposto aos demais alunos do grupo: “A mulher é 'a' e o homem é 'A' porque o homem domina”. A atribuição da dominância de um alelo sobre outro à relação entre gêneros evidencia o machismo presente na sociedade como senso comum e, por consequência, impregnado no dia a dia da aluna.

Outro exemplo de experiência de vida dos alunos levada para a sala foi observado na regência de um dos licenciandos que teve como tema a origem da vida de acordo com preceitos científicos, mas incluiu a apresentação de visões de diferentes culturas acerca do tema, como a ocidental cristã, japonesa, boshongo e maia. A proposta consistia em colocar os alunos em contato com formas de explicação pouco conhecidas e contrastantes com suas crenças pessoais, visto que a maioria professava a fé cristã - segundo Vieira (2011, p. 93), 58\% de um total de 261 alunos pesquisados em 2010 na mesma escola se declararam católicos ou evangélicos - e não tinha conhecimento de outras teorias de surgimento da vida que não fosse a ideia criacionista contida na bíblia. Boa parte dos alunos considerou as teorias apresentadas absurdas e hilárias, enfatizando suas certezas na ideia de que a vida teria sido criada por um deus especificamente cristão, o que invalidaria outras crenças.

O terceiro exemplo refere-se às aulas de genética sobre eritroblastose fetal. Embora não conhecessem o termo, algumas alunas que já são mães relataram que tomaram algum soro no momento do parto "Por causa do sangue do filho". A aula despertou o interesse dos estudantes, por aproximar o conteúdo escolar à vida cotidiana de alguns deles.

Entretanto, é importante ressaltar que o objetivo de eliminar as concepções prévias dos alunos e substituí-las por concepções científicas dificilmente se concretiza em qualquer nível de ensino, especialmente na EJA, e não deve ser buscado. Deve-se ter em mente que as diferentes formas de explicação dos fenômenos e da realidade que os estudantes trazem para a sala de aula podem coexistir com os conhecimentos científicos aprendidos na escola, desde que cada forma de explicação seja utilizada no contexto adequado (MORTIMER, 1996, p. 28). Dessa forma, por exemplo, é importante que o aluno saiba através da escola que a eritroblastose fetal é uma doença na qual a incompatibilidade de fator Rh entre o sangue da gestante e do bebê gera uma resposta imunológica no organismo materno, a fim de eliminar o "agente estranho" (fator $\mathrm{Rh}^{+}$) presente nas hemácias do filho. Na vida cotidiana, basta saber que o sangue da mãe é diferente do sangue do filho e a mistura entre eles seria potencialmente perigosa ao recém-nascido, podendo levá-lo à morte. 


\section{Desafio de atenção}

A maior parte do alunado do colégio acompanhado é formada por trabalhadores. De acordo com Vieira (2011, p. 99), 71\% dos 261 alunos participantes de sua pesquisa encontravam-se empregados em algum tipo de atividade remunerada. As aulas eram ministradas das $18 \mathrm{~h} 20 \mathrm{~min}$ às $22 \mathrm{~h} 40 \mathrm{~min} \mathrm{e}$, em uma reunião com os representantes de turma, quando apresentada a queixa dos professores sobre o atraso dos alunos, foi argumentado que muitos destes iam para a aula logo após o expediente de trabalho e os que exerciam atividade profissional no setor de comércio só eram liberados às $18 \mathrm{~h} 30 \mathrm{~min}$. A dupla jornada refletia negativamente em seu desempenho, visto que muitos deles chegavam à escola extremamente cansados e frequentemente atrasados, apresentando dificuldades em acompanhar as aulas.

Um dos exemplos mais marcantes diz respeito a um aluno que morava na zona rural de Nova Iguaçu, município da região metropolitana do Rio de Janeiro, localidade a mais de duas horas de distância do colégio. Segundo seu relato, era preciso que saísse da escola antes do último tempo de aula como forma de garantir o acesso a todos os ônibus necessários, utilizando o cartão de gratuidade. Além de perder no mínimo um tempo de aula todos os dias, esse aluno chegava à sua casa depois da meia-noite e acordava para o trabalho às cinco da manhã. A rotina pesada refletiu em seu desempenho, pois foi reprovado nos dois semestres de 2011.

Pensando no desafio de atenção, foram empregadas abordagens variadas para atenuá-lo. A maior parte das aulas era ministrada com uso do projetor, permitindo o uso de imagens, vídeos e esquemas virtuais, que as tornavam mais dinâmicas. Além disso, mudanças no formato de algumas aulas também foram bem-sucedidas. Exemplo disso foi a aula-debate sobre destinação do lixo e suas problemáticas, realizada em uma das turmas de primeiro ano, que teve boa receptividade por parte dos alunos. Estes foram divididos em três grupos - representando aterro sanitário, lixão e incineração - e cada um deveria pensar nas vantagens de sua forma de destinação e as desvantagens das demais. Ao final das discussões, cada grupo apresentou suas conclusões à turma. Os estudantes mostraram-se bastante envolvidos com a atividade e se aplicaram em aprender o conteúdo. Foi interessante observar que o aluno de mais idade, que se manifestava pouco durante as aulas, teve uma intensa participação, apresentando dados e argumentos históricos, políticos e sociais que enriqueceram o debate.

Outra estratégia frequente da professora consistia em, após apresentar o conteúdo, propor aos alunos que fizessem uma redação a respeito do tema, de forma que a proposta os fizesse elaborar uma análise crítica. Essas redações sempre procuravam levar o aluno a refletir sobre seu cotidiano a partir do conteúdo apresentado. Dois exemplos de propostas que levaram à produção de ótimos textos e discussões se referiam a tratamentos terapêuticos com o uso de células-tronco embrionárias - tema que gerava conflitos entre suas convicções filosóficas e religiosas e os benefícios que trariam para amigos ou familiares enfermos - e atitudes cotidianas e suas consequências ambientais locais, o que remeteu ao problemático acúmulo de lixo em algumas áreas da comunidade na qual muitos dos alunos moravam.

Ainda houve uma terceira estratégia utilizada que nos pareceu eficiente para a obtenção da atenção dos estudantes: a aplicação de estudos dirigidos na sala de aula. Os alunos eram divididos em grupos para a resolução das questões, o que era interessante para a dinâmica da atividade, pois encontravam-se em diferentes níveis de compreensão do conteúdo. Dessa forma, era possível observar que os alunos entendiam pontos diferentes da matéria, levando à complementaridade necessária para a realização do trabalho. Também, era possível perceber estudantes com maior domínio da matéria explicando-a aos demais, processo facilitado pela nova configuração da sala de aula, com grupos divididos em círculos de estudo. 
Observamos que, quanto mais próximo o conteúdo da rotina do estudante, maior sua atenção pelo assunto. Assim, estratégias de ensino variadas e a inclusão dos conhecimentos trazidos por eles configuram artifícios fundamentais para o professor obter sucesso perante o desafio da atenção - uma constante busca por cativar e envolver os alunos.

\section{Desafio da continuidade}

A retomada de conceitos prévios de alunos da EJA é frequentemente um entrave, pois essa modalidade de ensino é dirigida justamente ao indivíduo que teve sua formação descontinuada em algum momento da vida. O fato é que cada aluno teve um intervalo diferente em sua formação, do jovem repetente por vários anos proveniente do ensino regular até o idoso que pretende retomar os estudos após décadas de afastamento do ambiente escolar. Faz-se necessário, portanto, que o professor programe suas aulas sem presumir que os alunos possuam um conhecimento prévio profundo, assegurando-se que transitará dentro de um conhecimento inteligível por todos. No entanto, é importante que isso não torne a aula uma constante retomada de assuntos anteriores, pois aqueles que já possuem o conhecimento prévio podem passar a ver as aulas como repetitivas e cansativas, desmotivando-se.

Nosso primeiro contato com essa lacuna no conhecimento aconteceu na primeira aula de uma das turmas de primeiro ano, quando um aluno perguntou se uma árvore é um organismo autotrófico ou heterotrófico. Como essa era uma das questões do exercício proposto pela professora, o licenciando resolveu conduzi-lo à resposta através de algumas perguntas sobre o modo de obtenção de energia pelas plantas. Ao longo do diálogo, ficou claro que aquele estudante não tinha conhecimento de conceitos básicos esperados de um aluno cursando o ensino médio, como fotossíntese e seiva. Após assistir à cena, a professora regente comentou a importância de se verificar, constante e diretamente, se o aluno possui alguma noção dos termos ou conceitos necessários para a compreensão do assunto em questão.

Tal desafio também esteve presente na regência de um dos licenciandos sobre as observações feitas por Charles Darwin a bordo do navio Beagle. Ele pretendia abordar princípios de biogeografia e, para isso, retomaria conceitos das teorias de Tectônica de Placas e Deriva Continental. Apesar de ser esperado que alunos do primeiro ano do ensino médio conhecessem tal conteúdo, foi constatado previamente que não era o caso: a resposta foi a total estranheza. Assim, o licenciando explicou brevemente tais conceitos antes de iniciar os assuntos seguintes.

O desafio da continuidade é, portanto, a busca constante do sutil equilíbrio entre uma aula que apresente novidades, mas que não seja ininteligível para alguém que esteja sem contato com determinado conhecimento escolar há muitos anos e, ao mesmo tempo, não seja uma aula muito simples, que trate o aluno como uma tabula rasa.

\section{Desafio motivacional}

A EJA é uma modalidade de ensino que tem como um de seus alicerces a função reparadora (BRASIL, 2000, p. 7), pretendendo escolarizar o indivíduo que teve sua trajetória interrompida em algum momento da vida. Seu alunado é, por definição, composto por pessoas que retomam os estudos por algum motivo, seja por realização pessoal ou necessidade de obtenção do certificado de conclusão do ensino fundamental ou médio.

Exemplo marcante de tal desafio, observado durante a prática de ensino, diz respeito a uma das alunas mais idosas do colégio que estava retomando os estudos naquele ano. Ela contou para nós que desenvolveu certo bloqueio quanto às disciplinas, mesmo antes de ter 
contato com os conteúdos, e dizia que conseguia fazer os exercícios quando vinham após a explicação da matéria, mas que não sabia responder às questões nas provas. Por conta disso, ainda segundo a própria aluna, a maioria de suas provas era entregue em branco não porque não soubesse o conteúdo para responder às perguntas, mas por insegurança. A participação de um dos licenciandos foi fundamental para a elevação da autoestima da aluna em questão - sua presença na resolução dos exercícios ou explicação da matéria mudaram a forma como ela lidava com o conteúdo. Mesmo reprovando em ambos os semestres, ao final do ano, a aluna estava muito satisfeita por ao menos ter conseguido responder a algumas questões nas provas e ser aprovada em algumas matérias.

Essa aluna é um caso relativamente frequente da EJA: o indivíduo que está afastado do ambiente escolar há muito tempo e que, quando retorna a ele, não consegue lidar com suas práticas e rotina. Nada é natural: compreender os diferentes comandos das questões das provas e exercícios (cite, aponte, descreva, relacione, explique etc.), extrair elementos importantes das falas dos professores para anotá-los no caderno, a preocupação com o número de linhas de caderno a serem puladas entre o título e o texto da matéria passada no quadro, o uso do uniforme e toda uma série de rituais tipicamente escolares. A repetência, que seria algo natural até a pessoa se reacostumar com a escola, causa, em geral, um grande abalo no estudante.

Os alunos jovens que chegam à EJA geralmente buscam o certificado de conclusão para ingressar no ensino superior ou mercado de trabalho. O caráter burocrático que veem na obtenção do certificado faz com que muitos deles deem mais importância às notas e menos aos conhecimentos. Logo, uma repetência prejudica o fim que almejam, desmotivando-os, até pelo fato de grande parte desses jovens ter entrado na modalidade de ensino em questão depois de sucessivas repetências no ensino regular. Entretanto, seja no caso das repetências de jovens ou de adultos, um dos maiores fatores de influência sobre a motivação dos estudantes é quando o professor rotula o repetente como incapaz. É grave, inclusive, quando o professor da EJA encara seus alunos com qualquer tipo de preconceito. Segundo Vieira (2011, p. 15), “[...] negar que estes sujeitos sabem parece ser uma nova forma de colocar estes(as) alunos(as) à margem do conhecimento", e o aluno percebe qual professor o menospreza e qual aposta em seus potenciais.

Nos conselhos de classe e reuniões de professores em que estivemos presentes, foi possível concluir que os docentes que mais tinham reclamações por parte dos alunos eram os que menos sabiam lidar com as especificidades dos perfis de alunos dessa modalidade de ensino. Uma cena notável, que ilustra tal afirmação, foi relatada por alguns alunos durante uma reunião com a direção. Segundo os estudantes, um jovem perguntou à professora de determinada disciplina se o livro que ele tinha em mãos poderia ajudá-lo a se aprofundar em sua matéria. A docente, duvidando de sua capacidade, disse que deveria procurar outro livro, pois o aluno não seria capaz de chegar ao nível daquele material. De fato, mesmo antes desse relato, eram bastante recorrentes reclamações sobre os procedimentos da docente, como a aplicação de provas idênticas para todas as turmas de todas as séries do ensino médio.

A motivação parece-nos ser determinante para evitar a evasão do aluno da EJA, já que não há obrigatoriedade de sua permanência no colégio, como há para os alunos de até dezessete anos no ensino regular. Os desafios analisados anteriormente refletem diretamente na motivação do estudante e a taxa de $66 \%$ de evasão/repetência (dado fornecido pela secretaria da escola referente aos semestres letivos de 2011) mostra que a motivação desses alunos está ferida. Portanto, quanto maior o cuidado e respeito do professor com seu aluno, melhor. 


\section{Considerações finais}

Os desafios sobre os quais tratamos neste trabalho não são exclusivos da EJA, mas acreditamos que possuem uma dimensão diferente nesta modalidade de ensino em comparação com o ensino regular, devido à amplitude de perfis dos sujeitos nela inseridos.

Em nossa experiência como licenciandos, observamos que os professores que não empreendiam uma reflexão a respeito das particularidades do seu alunado eram exatamente aqueles de quem os alunos mais se queixavam. Indagações do tipo: "Como é que essa professora aplicou uma prova daquelas, se nem matéria no quadro ela passa pra gente?”, fizeram-nos notar que os alunos percebiam quais professores tinham a preocupação em elaborar aulas, atividades e avaliações que se adequassem a seus diferentes perfis, e retribuíam essa dedicação com demonstrações de afeto dentro e fora da sala de aula e com a deposição de confiança no docente. Tais percepções levavam os alunos a compartilhar relatos sobre dificuldades na vida escolar ou pessoal.

Observamos, também, como o professor desmotivado e mal preparado para trabalhar com um alunado tão específico pode minar seu interesse e aprendizagem. E, que esse docente, incapaz de notar e enfrentar os desafios adequadamente, pode contribuir para a desmotivação do aluno, levando a altas taxas de repetência e evasão. Fosse sempre dessa forma, a EJA perderia sua razão de ser.

Por outro lado, reconhecemos que as políticas neoliberais adotadas pelos órgãos governamentais de educação tratam de perverter a culpabilidade de uma educação de baixa qualidade ao professor, pois tomam para si a premissa de que sua parte está sendo contemplada: a universalização do ensino. Investe-se em criação de escolas, mas não há tanta preocupação com a formação inicial e continuada dos docentes, ratificando a opinião pública de que a melhoria da qualidade da educação brasileira só depende do professor.

Dessa forma, percebemos que mesmo o professor empenhado em fazer a diferença terá entraves burocráticos, questões pedagógicas e uma pluralidade do alunado que o desafiará constantemente dentro e fora da sala de aula. Essas peculiaridades sempre demandarão do docente maiores recursos didáticos, reflexões profundas sobre sua prática, estudo, renovação e disposição, o que, na maioria das vezes, dependerá de esforço próprio, haja vista as condições de trabalho às quais estão submetidos.

Objetivamos pontuar, portanto, que haja da parte do professor um cuidado e uma atenção ao lidar com os desafios que expusemos neste trabalho, mas que também haja da parte dos órgãos governamentais políticas públicas que incentivem e permitam que o professor possa se atentar às questões expostas.

\section{Referências}

BRASIL. Parecer CNE/CEB 11/2000. Institui as Diretrizes curriculares nacionais para a Educação de Jovens e Adultos. Brasília, 2000.

BRUNEL, Carmen. Jovens Cada Vez Mais Jovens na Educação de Jovens e Adultos. Porto Alegre: Editora Mediação, 2004.

DOTTORI, Cloves de Bittencourt (Coord.). Educação de Jovens e Adultos: Ensino Médio. Reorientação Curricular. Rio de Janeiro, 2006.

LOPES, Selva Paraguassu; SOUSA, Luzia Silva. EJA: uma educação possível ou mera utopia? CEREJA, v. 1, p. 1-20, 2005.

MORTIMER, Eduardo Fleury. Construtivismo, mudança conceitual e ensino de ciências: para onde vamos? Investigações em Ensino de Ciências, v. 1, n. 1, p. 20-39, mar. 1996. 
Sobre chamas e cristais: a linguagem cotidiana, a linguagem científica e o ensino de ciências. In: CHASSOT, Áttico; OLIVEIRA, Renato José de (Orgs.). Ciência, ética e cultura na educação. São Leopoldo: Editora UNISINOS, 1998. p. 99-118.

NASCIMENTO, Carmen Teresinha Brunel do. Jovens no ensino supletivo: reconstituindo trajetórias. 2001. 210 fs. Dissertação (Mestrado em Educação) - Universidade Federal do Rio Grande do Sul, Porto Alegre, 2001.

RIBEIRO, Vera Masagão. A formação de educadores e a constituição da educação de jovens e adultos como campo pedagógico. Educação e Sociedade, n. 68, p. 184-201, dez. 1999.

SILVA, Líbia Suzana Garcia da. Juvenilização na EJA: experiências e desafios. 2010. 108 fs. Trabalho de conclusão de curso (Licenciatura em Pedagogia) - Universidade Federal do Rio Grande do Sul, Porto Alegre, 2010.

VALE, Zoe Margarida Chaves. Encontros e desencontros entre os jovens e a escola: sentidos da experiência escolar na educação de jovens e adultos - EJA. 2007. 281 fs. Dissertação (Mestrado em Psicologia) - Universidade Federal de Minas Gerais, Belo Horizonte, 2007.

VIEIRA, Diana Sayão. Educação de Jovens e Adultos e Pluralidade Cultural: a realidade de um Colégio Supletivo de Ensino Médio. 2011. 147 fs. Dissertação (Mestrado em Educação) - Pontifícia Universidade Católica do Rio de Janeiro, Rio de Janeiro, 2011. 